Med Princ Pract 2019;28:498

DOI: $10.1159 / 000500440$

\section{Reply to Correspondence on "Glomerular Filtration Rate as a Prognostic Factor for Long-Term Mortality after Acute Pulmonary Embolism"}

\author{
Valdis G̦ïbietis ${ }^{\mathrm{a}, \mathrm{b}, \mathrm{d}}$ Dana Kigitoviča $^{\mathrm{a}, \mathrm{b}, \mathrm{d}}$ Barbara Vittola $^{\mathrm{a}, \mathrm{d}}$ \\ Sintija Strautmane Andris Skride $^{\mathrm{b}, \mathrm{d}}$ \\ ${ }^{a}$ Faculty of Continuing Education, Riga Stradins University, \\ Riga, Latvia; ${ }^{\text {b }}$ Department of Internal Medicine, Riga Stradins \\ University, Riga, Latvia; ' $F$ Faculty of Medicine, Riga Stradins

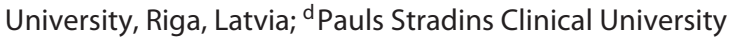 \\ Hospital, Riga, Latvia
}

We are pleased to respond to Ouatu and colleagues on our paper [1]. The results of our study were concordant with conclusions from the article by Ouatu et al. [2] showing that chronic renal dysfunction, assessed by glomerular filtration rate, may be used in the risk stratification of patients with non-high-risk pulmonary thromboembolism. Our study sample was largely similar to the cohort of the aforementioned study, mostly composed of normotensive, non-high-risk patients.

Age was identified as a significant factor associated with both 90-day and 1-year mortality in univariate analysis. It also demonstrated statistical significance in multivariate analysis of factors associated with 90-day mortality when renal function was assessed using the Modification of Diet in Renal Disease (MDRD) formula $(p=0.046)$. It is known that the Chronic Kidney Disease Epidemiology Collaboration (CKD-EPI) formula, which utilizes the same clinical parameters, is considered more prognostically accurate than the MDRD formula [3]. The CKD-EPI formula remained significant for mortality in multivariate analysis of both the 90-day and the 1-year follow-up period, whereas the MDRD formula failed to show significance for the 1-year follow-up. Overall, using the MDRD formula we identified 42 patients classified as having an eGFR $<60 \mathrm{~mL} / \mathrm{min}$, but according to the CKD-EPI formula there were 48 such patients. The CKD-EPI formula also had slightly higher AUC (area under the curve) values in ROC (receiver operating characteristic) curves. Thus, the fact that the MDRD formula was not shown to be significantly associated with 1-year mortality may be explained by the weaker diagnostic capability of this formula. We admit that the relatively low number of patients could have also influenced the result - all three formulas identified 11 patients with renal dysfunction (creatinine clearance $[\mathrm{CrCl}]$ or eGFR $<60 \mathrm{~mL} / \mathrm{min}$ ) who died in 90-day analysis. In the 1-year follow-up, however, the MDRD formula identified only 12 nonsurvivors with renal dysfunction, as opposed to 13 patients when using the Cockcroft-Gault or CKD-EPI formulas.

The Cockcroft-Gault formula is generally considered to be inferior to the MDRD and CKD-EPI formulas for the estimation of renal function, because it has not been expressed using standardized creatinine values [4]; however, it has been demonstrated to be prognos- tically useful with various cardiovascular diseases [5]. In our study it showed the highest AUC values in ROC curves and a significant association with mortality in both the 90 -day and the 1 -year period. A possible explanation for this finding may be the fact that a large proportion of our patients were overweight or obese; interestingly, the mean BMI was higher among survivors, a finding that has been demonstrated in a study by El-Menyar et al. [6]. The Cockcroft-Gault formula includes body weight, so this parameter might have had an impact on the estimated $\mathrm{CrCl}$ values; fewer patients were identified as having renal dysfunction, because a higher body mass is inversely related to the estimated $\mathrm{CrCl}$ value. As the survivors had a higher mean body mass, fewer of them had a low $\mathrm{CrCl}$; hence, the prognostic performance of the Cockcroft-Gault formula seemed to be higher.

To sum up, the Cockcroft-Gault formula showed its potential usefulness for risk stratification in our study, and so did the CKDEPI formula. Also, the Cockcroft-Gault formula remains relevant because of its use in renal dose adjustment recommendations in drug descriptions for patients receiving drugs with renal elimination, e.g., oral anticoagulants.

Atrial fibrillation in any form was observed in 28 patients (19.9\%); however, we did not find a statistically significant association with mortality. We agree that renal dysfunction at the moment of diagnosis of pulmonary embolism and its assessment using different formulas in association with prognosis in patients with venous thromboembolism remains a matter of debate. Also, our study is ongoing, and our patient cohort is increasing, and thus outcomes from a larger population are awaited.

Disclosure Statement

The authors declare no conflicts of interest.

\section{References}

1 Giibietis V, Kigitoviča D, Vìtola B, Strautmane S, Skride A. Glomerular filtration rate as a prognostic factor for long-term mortality after acute pulmonary embolism. Med Princ Pract. DOI: 10.1159/000497436.

2 Ouatu A, Tãnase DM, Floria M, Ionescu SD, Ambãruş V, ArsenescuGeorgescu C. Chronic kidney disease: prognostic marker of nonfatal pulmonary thromboembolism. Anatol J Cardiol. 2015 Nov;15(11):938-43.

3 Tarantini L, Barbati G, Cioffi G, McAlister FA, Ezekowitz JA, Mazzone C, et al. Clinical implications of the CKD Epidemiology Collaboration (CKD-EPI) equation compared with the Modification of Diet in Renal Disease (MDRD) study equation for the estimation of renal dysfunction in patients with cardiovascular disease. Intern Emerg Med. 2015 Dec; 10(8):955-63.

4 Levey AS, Stevens LA. Estimating GFR using the CKD Epidemiology Collaboration (CKD-EPI) creatinine equation: more accurate GFR estimates, lower CKD prevalence estimates, and better risk predictions. Am J Kidney Dis. 2010 Apr;55(4):622-7.

5 Barra S, Providência R, Faustino C, Paiva L, Fernandes A, Leitão Marques A. Performance of the Cockcroft-Gault, MDRD and CKD-EPI formulae in non-valvular atrial fibrillation: which one should be used for risk stratification? J Atr Fibrillation. 2013 Oct;6(3):896.

6 El-Menyar A, Asim M, Al-Thani H. Obesity paradox in patients with deep venous thrombosis. Clin Appl Thromb Hemost. 2018 Sep;24(6): 986-92.

\section{KARGER}

E-Mail karger@karger.com www.karger.com/mpp
(C) 2019 The Author(s)

Published by S. Karger AG, Basel

Karger

Open access

This is an Open Access article licensed under the Creative Commons Attribution-NonCommercial-4.0 International License (CC BY-NC) (http://www.karger.com/Services/OpenAccessLicense), applicable to the online version of the article only. Usage and distribution for commercial purposes requires written permission.
Valdis Gỉbietis

Faculty of Continuing Education, Riga Stradins University

16 Dzirciema Street

LV-1007 Riga (Latvia)

E-Mail valdisgib@gmail.com 